\title{
Project of a universal inverter used to control and supply both $A C$ and DC electric motors
}

\author{
Wojciech Ludowicz ${ }^{1, *}$, Dawid Danielczyk ${ }^{1}$ and Rafat M. Wojciechowski ${ }^{1}$ \\ ${ }^{1,2,3}$ Poznan University of Technology, Institute of Industrial Electrical Engineering, Piotrowo 3a, 61-138, Poznan, Poland
}

\begin{abstract}
The paper presents the new approach for motor driver constructions and control systems. Authors of the work proposed the device that can control both AC and DC electric motors without any additional hardware modification. In order to meet this goal the universal motor driver has been constructed and some improvements in output waveform modulation system have been introduced. In the paper the three different method of a motor control have been discussed briefly and a hardware setup has been presented. Tests have been carried out for three types of electric motors, i.e. a magnetoelectric DC motor, single-phase and three-phase induction motor. The obtained results in form of output waveforms of current and voltage have been analyzed in terms of harmonic distortion using a popular Fast Fourier Transform FFT and discussed in the paper.
\end{abstract}

\section{Introduction}

The observed trend of mass use of power electronic converters that supply a wide range of electric motors and also declining costs of electronic components determine the creation of ever-newer, universal structures of inverters with a wide range of application and high reliability [1]. Furthermore, a huge progress in embedded microcontrollers systems have been done in recent years. It contributes to the development of more and more complex modulation methods that can be applied in modern inverters [2]. Therefore, in this paper, the Authors propose a design for the construction of a universal low-power inverter dedicated to supply of various types of electrical motors.

\section{Modulation methods}

In the constructed motor driver three different modulation methods used to driving electric motors have been applied. The first from considered methods, called the Space Vector Modulation Method SVPWM, is used to control three-phase electric motors [3]. Recently, the growing interest in this type of modulation results in many intriguing literature positions [4]. In the presented article the symmetric 7-segment switching technique with usage of both null vectors has been implemented. Besides two null vectors, there are six active vectors $V_{1}, V_{2} \ldots V_{6}$ in six separate sectors. Equation (1) describes fundamental relation of the SVPWM for the first sector [5].

$$
\vec{V}_{r e f}=\frac{T_{1}}{T_{s}} \vec{V}_{1}+\frac{T_{2}}{T_{s}} \vec{V}_{2}
$$

where: $V_{r e f}$ is the reference vector, $T_{s}$ is the sampling period of the SVPWM, $T_{1}$ and $T_{2}$ are duration times of vectors $V_{1}$ and $V_{2}$ respectively.

The second modulation method that has been applied in the motor driver is called Sine Pulse Width Modulation SPWM and combines advantages of standard Pulse Width Modulation PWM method of the sine wave and the Direct Digital Synthesis DDS modulation method [6]. A control algorithm generates a sine PWM signal basing on declared output waveform parameters like output frequency and switching frequency. Calculations are executed according to equation (2).

$$
f_{\text {out }}=\frac{M \cdot f_{s}}{P S C \cdot m \cdot(n \cdot A R R+2)(A R R+1)}
$$

where: $M$ is a control word, $m$ is the number of modulated halves of the sine wave, $n$ is the number of modulated quarters of the sine wave, ARR is the AutoReload Register of STM32 microcontroller, $f_{s}$ is the switching frequency, $f_{c l k}$ is the frequency of the clock of the microcontroller and PSC is the prescaler register of STM32 microcontroller.

The third modulation method applied in the project is direct current PWM modulation [7]. It enables control of the DC motors by controlling the average value of output voltage over a period of the PWM signal.

\section{Construction of universal inverter}

The developed inverter is designed to work with both AC and DC motors, with a rated power not exceeding $800 \mathrm{~W}$ and a rated supplying DC voltage up to $80 \mathrm{~V}$. A special feature of this design is the modular structure of the inverter, where can be distinguished six separate "blocks" 
responsible for different functions. In the project, modules in charge of: power supply, control, calculations, measurements and interface can be singled out. Usage of such an approach enables to increase the reliability of the system and simplify diagnostic procedures in case of failure. The structure is shown in Figure 1.

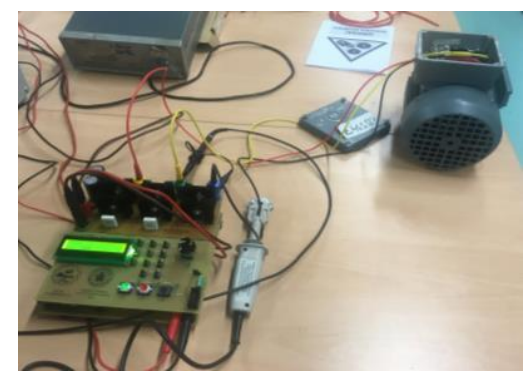

Fig. 1. The hardware setup of the constructed inverter.

\section{Selected results}

Tests have been carried out for three different electric motors in order to verify output waveform harmonic distortion. Therefore, Authors have used the FFT analysis to transform output waveforms of a line-to-line voltage and phase current of the tested motor into frequency spectrum. The obtained results for the threephase induction motor can be observed in Figure 2.

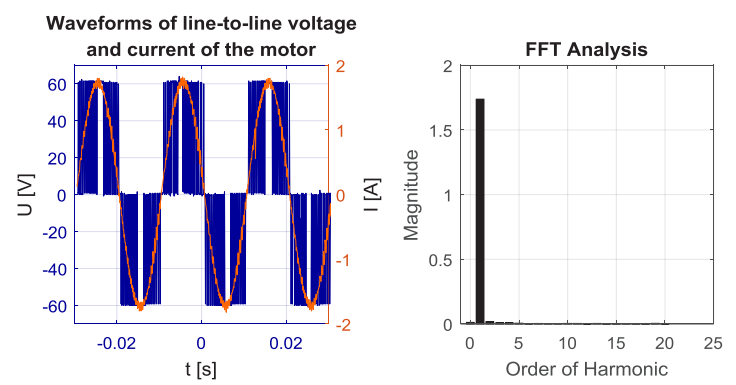

Fig. 2. The waveforms of the line-to-line voltage and phase current for the three-phase induction motor at frequency of $50 \mathrm{~Hz}$ and corresponding FFT current analysis.

Similar tests have been also applied for single-phase induction motor and magnetoelectric DC motor using respectively SPWM and standard DC PWM modulation methods. Results have been presented in Figures 3 and 4.

It can be observed that the best results of sine wave modulation have been obtained for SVPWM method. In case of SPWM method the contents of higher harmonic is more significant. However, in both cases the Total Harmonic Distortion THD factor is low and does not exceeded $1.5 \%$ for SVPWM and $2.5 \%$ for SPWM.

In Figure 4, for DC PWM method, some fluctuation in the output current can be observed. However, they result from commutation law of inductive circuit. It is clearly seen that along with decrease of the duty cycle, the average output current value decrease proportionally.

\section{Conclusion}

In the work the prototype of novel universal inverter for supplying both AC and DC electric motors has been proposed. Authors have discussed particular modulation methods that have been applied in the work, and also have presented and explained both basic equations and correlation. The obtained results have been verified in terms of higher harmonic contents using FFT analysis. Tests that have been carried out proof high standard of output waveform quality and low value of THD factor.
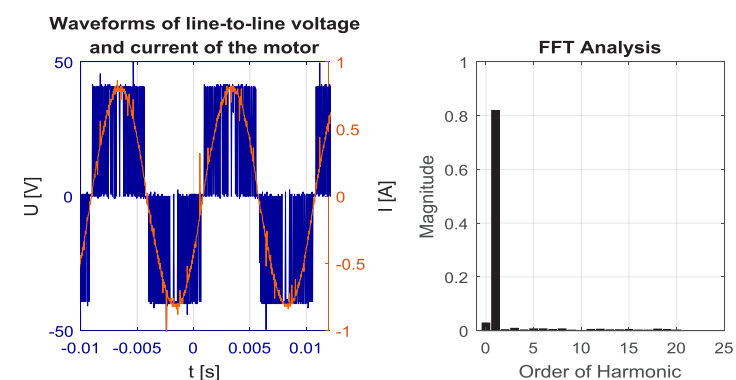

Fig. 3. The waveforms of the line-to-line voltage and phase current for the single-phase motor at frequency of $100 \mathrm{~Hz}$ and corresponding FFT current analysis.

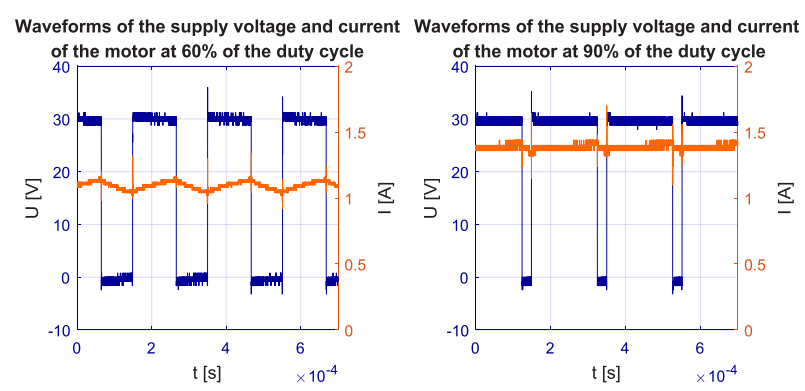

Fig. 4. Supply voltage and current of the magnetoelectric DC motor at duty cycle equal to $60 \%$ and $90 \%$ respectively.

\section{References}

1. M. Stalnaya, S. Eremochkin, I. Ivanov, Universal and energy efficient transistor autonomous inverter on semiconductor switches, Proc. of ACED, 26-30 March, Ekaterinburg, Russia (2018)

2. L. Yujuan, W. L Yun, Q. Zhongyi, R. Z. Navid and C. Zhongyuan, SVM strategies for common-mode current reduction in transformerless current-source drives at low modulation index, IEEE Trans. Power Electron, 32, 2 (2017)

3. S. Zeliang, T. Jian, G. Yuhua and L. Jisan, An efficient SVPWM algorithm with low computational overhead for three-phase inverters, IEEE Trans. Power Electron,. 22, 5 (2007)

4. L. Zhan, W. Yu, T. Guojun, C. Hao L. and Z. Yunfeng, A novel SVPWM algorithm for five-level active neutral-point-clamped converter, IEEE Trans. Power Electron, 31, 5 (2016)

5. L. Dong-Choon and L. G-Myoung, A novel overmodulation technique for space-vector PWM inverters, IEEE Trans. Power Electron, 13, 6 (1998)

6. W. Pietrowski, W. Ludowicz and R. M. Wojciechowski, The wide range of output frequency regulation method for the inverter using the combination of PWM and DDS, COMPEL, 38, 4 (2019) (will be published)

7. P. W. Franklin, Theory of the D. C. Motor Controlled by Power Pulses Part I - Motor Operation, IEEE Transactions on Power Apparatus and Systems, PAS-91, 1 (1972) 